\title{
Assessment of Health Related Quality of Life (HRQoL) in Patients with Chronic Diseases
}

\author{
Mohammed Safeer V S, Dr M Umesh* \\ Department of Pharmacy practice, JSS College of Pharmacy Mysuru, JSS Academy of Higher Education and Research, Sri \\ Shivarathreeshwara Nagara, Mysuru- Karnataka, India 570015. \\ *Corresponding author's E-mail: mumesh@jssuni.edu.in
}

Received: 14-03-2021; Revised: 18-05-2021; Accepted: 26-05-2021; Published on: 15-06-2021.

\begin{abstract}
According to various studies conducted on $\mathrm{HRQ}$ oL it was found that patient counselling provided by a pharmacist play an appreciable role in improving the $\mathrm{HRQoL}$ of the patients. Patient counselling plays a pivotal role in improving patient understanding about the disease and medications. Patient counselling can be provided through various mediums such as face-to-face counselling, patient information leaflets. The HRQoL of the patients can be assessed using various questionnaires available. The aim of the study is to assess influence of pharmacist provided counselling on improving the Health related quality of life (HRQoL) in patients with chronic diseases. Over a period of nine months, a prospective interventional study was held in the department of General Medicine JSS Hospital, Mysuru. Ethics committee approval was obtained for this study. Patients that fulfilled the requirements were included in the research and were educated about the disease, medications, importance of medication adherence and lifestyle modifications. All the necessary data have been gathered and recorded. The HRQoL was determined before and after educating using HRQoL (SF-20) questionnaire respectively. Paired student t-test had been used to compare the pre and post HRQoL scores. Out of 227 subjects admitted in the study, 66(29\%) had Diabetes Mellitus, 55(24\%) had been diagnosed with hypertension, 52(23\%) had been diagnosed with stroke and $54(24 \%)$ were diagnosed with bronchial asthma. All the study participants with different chronic disease were given with the HRQoL questionnaire before education (baseline) and after education (follow up). There was a significant increase in the patients' HRQoL scores after education as $p$-value which has been calculated was $<0.001$. Educating or counselling the patients regarding disease, medication and medication adherence helps in improving the Health related quality of life (HRQoL) in chronic disease patients.
\end{abstract}

Keywords: HRQoL, chronic disease, questionnaire, Hypertension, Stroke, Diabetes Mellitus, Bronchial asthma.

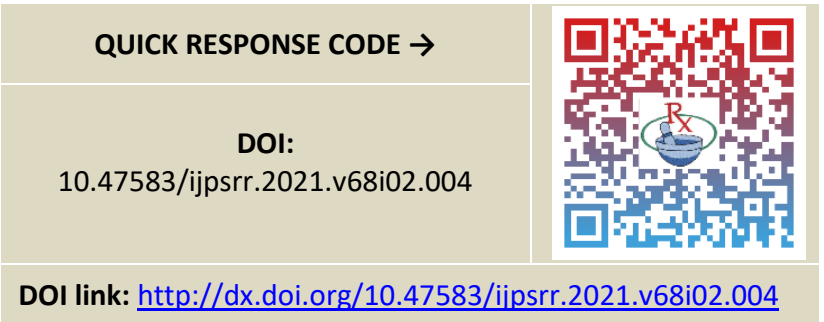

\section{INTRODUCTION}

$\mathrm{t}$ the turn of the millennium, chronic diseases are becoming the greatest challenge to global health. Conditions such as cardiovascular diseases, diabetes, obesity, cancer, lung diseases, depression, along with risk factors such as smoking, diet and physical activity, should be primary area of concern. ${ }^{1}$ Chronic diseases, particularly cardiovascular disease, type 2 diabetes, cancer, and chronic respiratory disease, account for more than $50 \%$ of mortality worldwide. ${ }^{2}$

When an individual develops more than one chronic disease, the picture gets more complicated. One in three adults worldwide have multiple chronic conditions: cardiovascular disease alongside diabetes, depression as well as cancer, or a combination of three, four, or even five diseases at the same time. ${ }^{1}$
Health-related quality of life (HRQOL) has become increasingly important in clinical research over the past decade. It provides a multidimensional perspective which encompasses the emotional, physical, and social functioning of a patient. HRQOL is linked to an individual's understanding of the role in life in the sense of culture and value systems and is complexly shaped by the physical health, psychological condition, maturity level and social relationships of the person. By establishing a link between the disease and HRQOL, then developing interventions aiming at improving HRQOL will become a new relevant therapeutic objective in the modern world of healthcare system. ${ }^{3}$

Therefore, a collaborative approach of patient care where physicians, pharmacists and nurses provide counseling regarding the disease and medications play a pivotal role in the healthcare system. The aim of the study is to assess or to evaluate the effect of clinical pharmacist provided counselling in improving the health-related quality of life (HRQoL) in chronic disease patients.

\section{MATERIALS AND METHODS}

\section{Study Site}

The research was carried out in the inpatients admitted to General Medicine Department, JSS hospital, Mysuru, 
which is a multi-specialty tertiary care teaching Hospital with 1800 beds.

\section{Study period}

The research was performed over a nine-month period from July 2019 to March 2020.

\section{Study Design}

The study was a prospective interventional study.

\section{Institutional Ethical Committee}

Ethical approval for this study was obtained from the institutional Human Ethical Committee of JSS College of Pharmacy, Mysuru prior to the commencement of the study.

\section{Study Criteria}

\section{Inclusion criteria}

$\checkmark \quad$ Inpatients admitted to Department of General Medicine.

$\checkmark \quad$ Patients of either gender

$\checkmark \quad$ Patients who are 18 years of age and older

\section{Exclusion Criteria}

$$
\begin{aligned}
& \checkmark \quad \text { Patient who are critically ill } \\
& \checkmark \quad \text { Patients who are not able to communicate } \\
& \checkmark \quad \text { Patient who does not want to sign an informed }
\end{aligned}
$$

\section{Sources of Data}

All the relevant and necessary Data were collected from

- Interaction with the patient

- Questionnaire

- Patient's case notes

- Patient treatment charts

- Other relevant sources

\section{HRQoL questionnaire (SF-20)}

The SF-20 which was established in 1988 as part of the Medical Outcome Survey (MOS) was used in this study to assess the health related quality of life (HRQoL) in chronic disease patients. It was first published in the journal medical care as the MOS short form general health survey. This questionnaire measures the health in 6 fields. It includes physical function (6 questions), perceptions of health (5 questions), functioning of roles ( 2 questions), mental health (5 questions), pain (1 question) and social functioning (1 question). Scores are calculated in each domain from $0 \%$ to $100 \%$, where $0 \%$ indicates that subject is having poor health and $100 \%$ indicates that the subject is having perfect health. The short form (SF-20) questionnaire on reliability and validity was first published in the Publications of the American Medical Association. ${ }^{4}$

\section{Study Procedure}

- SF-20questionnaire was used to asses Health related quality of life (HRQoL) in patients with chronic disease.

- A standard validated patient information leaflet was taken for all the chronic disease condition which is included in the study.

- Data collection forms were prepared.

- Informed consent was obtained from the subjects to be enrolled in the study

- Patients who were admitted to the hospital in general medicine department with chronic diseases like diabetes mellitus, hypertension, asthma and stroke is reviewed on daily basis.

- Patients meeting the research requirements were enrolled in the research.

- Health related quality of life (HRQoL) questionnaire (SF-20) was administered to inpatients at the time of admission and briefly explain to all the participants about the study and their responses were documented.

- Patients were counselled on different aspects of chronic diseases.

- Patient information Leaflets was provided to the patients.

- Health related quality of life (HRQoL) questionnaire (SF-20) was re-administered to the patients at the time of follow up.

- All the collected data were further reviewed and evaluated

\section{Data Analysis}

The Pre-interventional and post-interventional HRQoL scores were compared using a paired student t-test using SPSS 20.0 .

\section{RESULTS AND DISCUSSIONS}

\section{Assessment of HRQoL}

A total of 243 patients participated in the study with various chronic diseases where 227 study participants completed the study by successfully answering all the baseline and follow up questionnaire. Of the total 227 patients, 66(29\%) were diagnosed with Diabetes Mellitus, $55(24 \%)$ were diagnosed with hypertension, 52(23\%) were diagnosed with stroke and 54(24\%) were diagnosed with bronchial asthma. 
Table 1: Demographics of chronic disease patients

\begin{tabular}{|c|c|c|}
\hline SI.no & Patient Characteristics & $\begin{array}{c}\text { Number of Subjects } \\
\qquad \mathbf{N}(\%)\end{array}$ \\
\hline 1. & $\begin{array}{c}\text { Gender } \\
\text { Male } \\
\text { Female }\end{array}$ & $\begin{array}{l}121(53 \%) \\
106(47 \%)\end{array}$ \\
\hline 2. & $\begin{array}{c}\text { Age } \\
\text { 20-29 years } \\
\text { 30-39 years } \\
\text { 40-49 years } \\
50-59 \text { years } \\
>=60 \text { years }\end{array}$ & $\begin{array}{c}11(4.8 \%) \\
15(6.6 \%) \\
27(11.8 \%) \\
55(24.2 \%) \\
129(56.8 \%)\end{array}$ \\
\hline 3. & $\begin{array}{c}\text { Educational status } \\
\text { Illiterate } \\
\text { Primary } \\
\text { Middle } \\
\text { High School } \\
\text { Diploma } \\
\text { Graduate } \\
\text { Professional Degree }\end{array}$ & $\begin{array}{c}83(36.5 \%) \\
56(24.6 \%) \\
31(13.6 \%) \\
18(7.9 \%) \\
23(10.1 \%) \\
11(4.8 \%) \\
5(2.2 \%)\end{array}$ \\
\hline
\end{tabular}

\section{Diabetes Mellitus}

\section{Patient Characteristics}

Out of 66 patients enrolled in the study with Diabetes mellitus, 37 (49\%) of them were male and 39 (51\%) were female. Patients of all age groups ( $>18$ years) were included in the study. $4.54 \%$ of them belonged to the age group of 20-29 years, $12.1 \%$ of them in 30-39 years, $18.18 \%$ of them in $40-49$ years, $27.2 \%$ of them in $50-59$ years and $37.87 \%$ of the patients were above 60 years of age. Among 66 patients 28 (42.42\%) were illiterate, 12 (18.18\%) were educated till primary school, 8 (12.12\%) were having middle school education, 4 (6.06\%) were educated till high School, 10(15.15\%) were having diploma, $3(4.54 \%)$ were graduates and $1(1.51 \%)$ is having a Professional degree.

\section{Health related quality of life (HRQoL) Score}

The SF-20 questionnaire measures the health in 6 fields. It includes physical function (6 questions), perceptions of health (5 questions), functioning of roles ( 2 questions), mental health (5 questions), pain (1 question) and social functioning (1 question). Scores are calculated in each domain from $0 \%$ to $100 \%$, where $0 \%$ indicates that subject is having poor health and $100 \%$ indicates that the subject is having perfect health except in case of pain where $100 \%$ indicate that the subject is having severe pain and $0 \%$ indicates no pain. ${ }^{4,5}$

The physical functioning score at baseline was found to be $41.62 \pm 4.5$ and was increased to $56.65 \pm 3.2$ at the time of follow up. All the domains of health which includes role functioning (46.74 \pm 2.17$)$, social functioning (37.64 \pm 3.54$)$, mental health $(41.42 \pm 2.46)$, Health perceptions $(47.61 \pm 1.85)$ and pain $(52.73 \pm 2.25)$ showed an significant increase in their score to $(65.56 \pm 3.26),(66.3 \pm 1.25)$, (62.5 \pm 2.19$),(66.58 \pm 1.85)$ and $(28.18 \pm 4.65)$ respectively at the time of follow up. The $p$ value was found to be $<0.001$. A $p$ value $<0.05$ shall be considered statistically significant. Thus, the study concludes that a pharmacist provided counselling or education helps in improving quality of life in Diabetes patients.

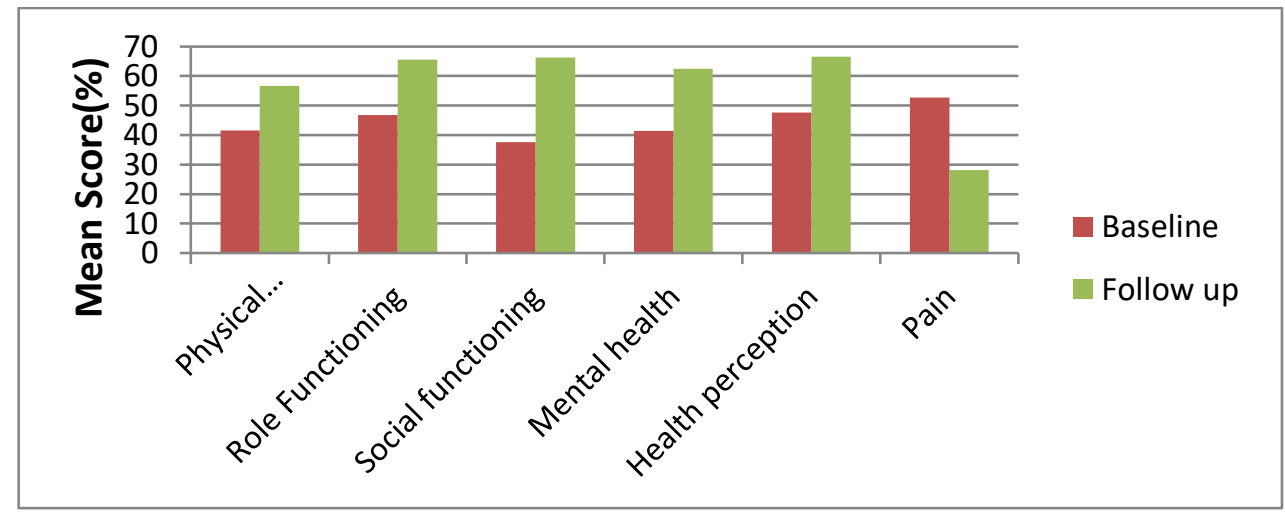

Figure 1: HRQoL scores of Diabetes patients at baseline and follow up

\section{Hypertension}

\section{Patient Characteristics}

Out of 55 patients enrolled in the study with Hypertension, $30(55 \%)$ of them were male and $25(45 \%)$ were female. Patients of all age groups ( $>18$ years) were included in the study. $3.6 \%$ of them belonged to the age group of $20-29$ years, $1.8 \%$ of them in $30-39$ years, $7.2 \%$ of them in $40-49$ years, $25.4 \%$ of them in $50-59$ years and $61.8 \%$ of the patients were above 60 years of age. Among 55 patients 23 (41.8\%) were illiterate, 12 (21.8\%) were educated till primary school, $9(16.3 \%)$ were having middle school education, $3(5.4 \%)$ were educated till secondary education, 4 (7.2\%) were having senior secondary education, 2 (3.6\%) were graduates and $2(3.6 \%)$ were postgraduates. 


\section{Health related quality of life (HRQoL) Score}

The physical functioning score at baseline was found to be $41.9 \pm 3.2$ and was increased to $59.8 \pm 5.3$ at the time of follow up. All the domains of health which includes role

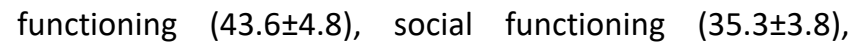
mental health $(43.6 \pm 3.2)$, Health perceptions $(45.6 \pm 4.6)$ and pain $(58.6 \pm 1.9)$ showed a significant increase in their score to $(63.05 \pm 1.2),(60.8 \pm 2.7),(52 \pm 3.5),(64.3 \pm 4.8)$ and $(32 \pm 3.9)$ respectively at the time of follow up. The $p$ value was found to be $<0.001$. A $p$ value $<0.05$ shall be considered statistically significant. The quality of life of patients has been statistically improved in all domains, hence the study concludes that a pharmacist provided counseling helps in improving the quality of life of the hypertensive patients.
Naveen et al conducted a study to evaluate the effect of clinical pharmacist provided education to improve quality of life in patients with hypertension. A total of 130 patients were admitted in the study. To assess the quality of life SF 36 v2 questionnaire was used. This questionnaire was administered at baseline and the patient was counseled regarding the disease, Lifestyle modification etc. The questionnaire was re-administered during the first and second follow up and BP was also recorded. They found that there was a significant increase in the quality of life of patients in all the domains of health. Thus, the study concludes that a pharmacist provided counseling can improve the quality of life of hypertensive patients. ${ }^{6}$

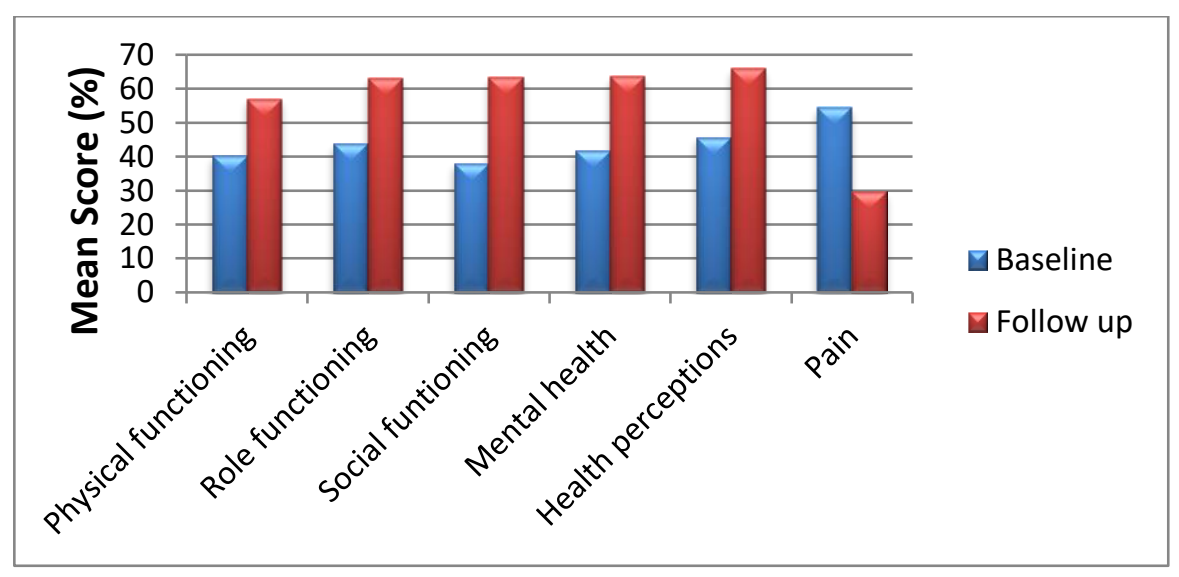

Figure 2: HRQoL scores of Hypertensive patients at baseline and follow up

\section{Stroke}

\section{Patient characteristics}

Out of 52 patients enrolled in the study with Stroke, 29 $(56 \%)$ of them were male and 23 (44\%) were female. Patients of all age groups ( $>18$ years) were included in the study. $1.9 \%$ of them belonged to the age group of $20-29$ years, $5.7 \%$ of them in $30-39$ years, $11.5 \%$ of them in $40-49$ years, $21.1 \%$ of them in $50-59$ years and $62 \%$ of the patients were above 60 years of age. Among 52 patients 18 (34.6\%) were illiterate, 10 (19.2\%) were educated till primary school, 4 (7.6\%) were having middle school education, 8 (15.3\%) were educated till high school, 7 (13.4\%) were having diploma, 4 (7.69\%) were graduates and $1(1.9 \%)$ is having a professional degree.

\section{Health related quality of life score (HRQoL)}

The physical functioning score at baseline was found to be $40.3 \pm 1.9$ and was increased to $56.9 \pm 4.9$ at the time of follow up. All the domains of health which includes role functioning (43.8 \pm 4.3$)$, social functioning (38.04 \pm 4.8$)$, mental health $(41.7 \pm 2.3)$, Health perceptions $(45.7 \pm 1.3)$ and pain $(54.3 \pm 4.6)$ showed an significant increase in their score to $(63.06 \pm 4.8),(63.25 \pm 5.3),(63.5 \pm 4.6),(65.9 \pm 3.3)$ and $(29.7 \pm 3.6)$ respectively at the time of follow up. The $p$ value was found to be $<0.001$. A $p$ value $<0.05$ shall be considered statistically significant. The quality of life of patients has been statistically improved in all domains, hence our study suggests that a pharmacist provided counseling helps in improving the quality of life of stroke patients.

Gurcay et al carried out a research to determine the factors that predict $\mathrm{HRQ}$ oL in stroke survivors. It is a cross-sectional study involving 67 first-time stroke patients treated at the Ankara Diskapi Yildirim Beyazit Education and Research Hospital, Physical Therapy and Rehabilitation Clinic. Stroke Impact Scale (SIS-16) was used to assess the HRQoL. Patients were divided based on the age, sex, functional status (Functional Independence Measure [FIM]), cognitive function (Mini-Mental State Examination [MMSE]). They found in the study that age and functional status had a major influence on the HRQoL. ${ }^{7}$

\section{Bronchial asthma}

\section{Patient characteristics}

Out of 54 patients enrolled in the study with Bronchial asthma, 25 (46\%) of them were male and 29 (54\%) were female. Patients of all age groups ( $>18$ years) were included in the study. $9.2 \%$ of them belonged to the age group of 20 29 years, $5.5 \%$ of them in $30-39$ years, $9.2 \%$ of them in 40 49 years, $22.2 \%$ of them in $50-59$ years and $53.7 \%$ of the patients were above 60 years of age. Among 52 patients 14 (25.9\%) were illiterate, 22 (40.7\%) were educated till primary school, 10 (18.5\%) were having middle school education, 3 (5.5\%) were educated till high school, 2 (3.7\%) were having diploma, 2 (3.7\%) were graduates and 1 (1.8\%) is having a professional degree. 


\section{Health related quality of life (HRQOL) score}

The physical functioning score at baseline was found to be 41.6 \pm 1.5 and was increased to $58.1 \pm 3.4$ at the time of follow up. All the domains of health which includes role

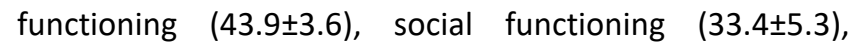
mental health $(43.7 \pm 1.2)$, Health perceptions $(46.4 \pm 4.6)$ and pain(51.5 \pm 2.3$)$ showed an significant increase in their score to (63.09 \pm 4.5$),(60.5 \pm 5.7),(63.4 \pm 2.4),(65.6 \pm 4.7)$ and $(28.2 \pm 5.04)$ respectively at the time of follow up. The $p$ value was found to be $<0.001$. A $p$ value $<0.05$ shall be considered statistically significant. The quality of life of patients has been statistically improved in all domains, hence our study suggests that a pharmacist provided counseling helps in improving the quality of life of bronchial asthma patients.

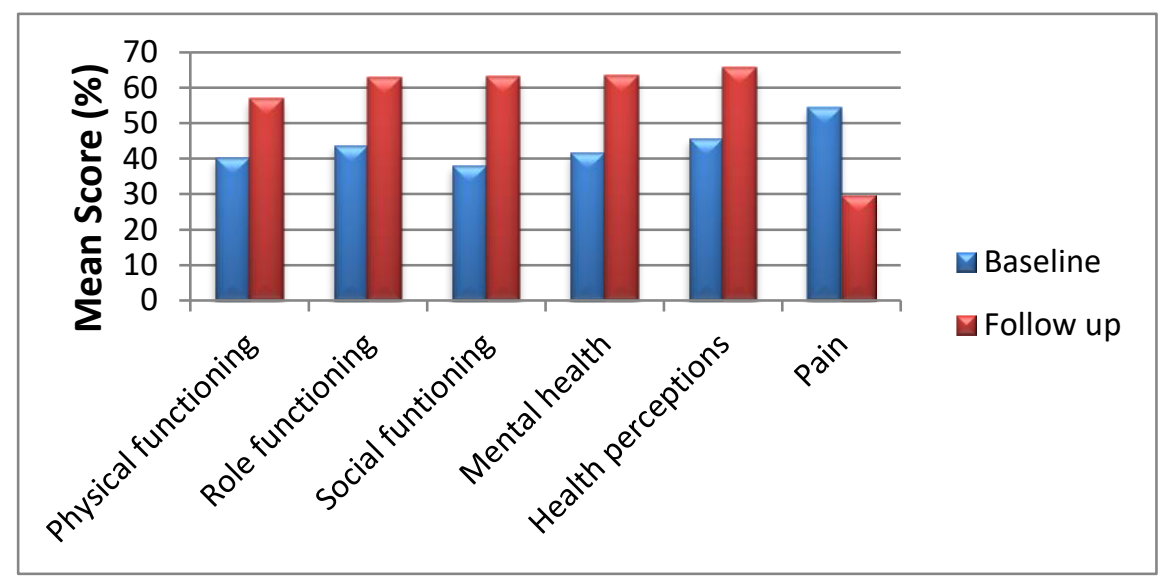

Figure 3: HRQoL scores of stroke patients at baseline and follow up

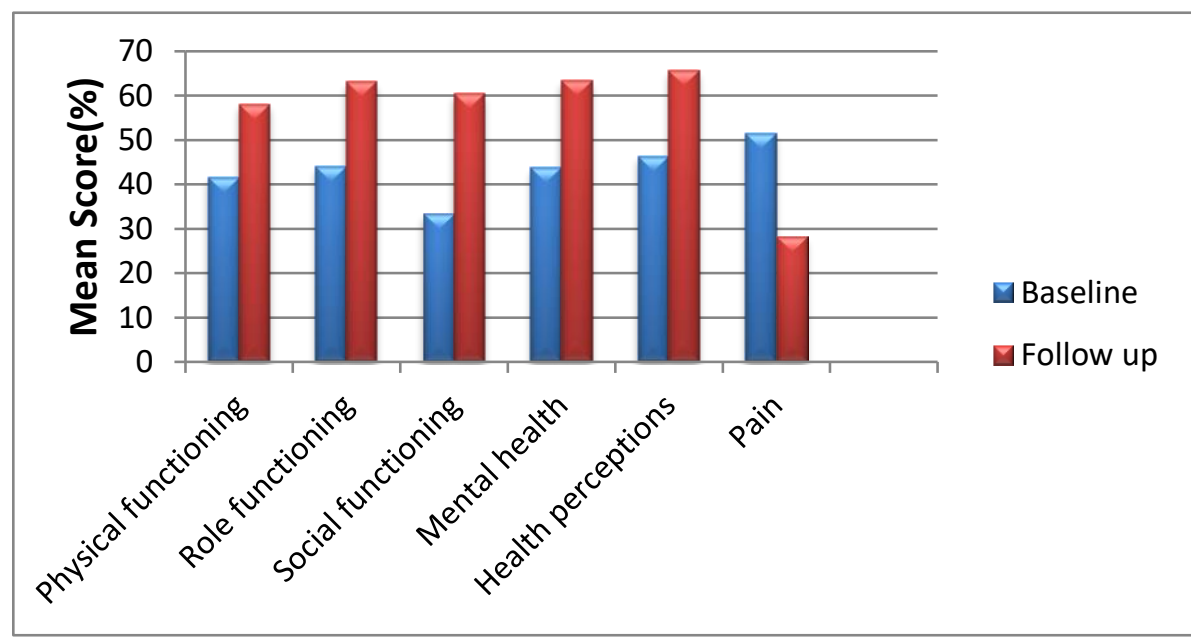

Figure 4: HRQoL score of bronchial asthma patients at baseline and follow up

\section{CONCLUSION}

In this study, the patient was counseled regarding the disease, medications used for the disease and also the importance of medication adherence and lifestyle modifications. Patient also received patient information leaflets for their disease. Out of 227 patients enrolled in the study 66(29\%) were diagnosed with Diabetes Mellitus, 55 (24\%) were diagnosed with hypertension, 52(23\%) were diagnosed with stroke and 54(24\%) were diagnosed with bronchial asthma, where these patients received counselling specific to their disease. The health related quality of life (HRQoL) was also assessed using SF-20 questionnaire. There was also a substantial increase in quality of life of the patients after patient education. This study concludes that Health related quality of life (HRQoL) of the patients can be significantly increased through patient education. Thus, pharmacist plays a crucial role in educating the patient regarding the disease, importance of medication adherence and lifestyle modification.

\section{Author's contributions}

Mohammed Safeer v s carried out the study, and $\operatorname{Dr} M$ Umesh reviewed and edited the manuscript.

\section{Acknowledgments}

The authors would like to acknowledge the support and infrastructure from the principal, JSS College of Pharmacy, Mysuru.

\section{Abbreviation}

HRQoL: Health related quality of life 


\section{REFERENCES}

1. Adler-Waxman A, Teva. This is the biggest challenge to our health [Internet]. World Economic Forum. [cited 2020 Apr 9]. Available from: https://www.weforum.org/agenda/2017/12/healthca re-future-multiple-chronic-disease-ncd/.

2. Yach D, Leeder SR, Bell J, Kistnasamy B. Global Chronic Diseases [Internet]. Science. American Association for the Advancement of Science 2005 [cited 2020 Apr 9]. Available from: https://science.sciencemag.org/content/307/5708/31 7.full

3. Xu X, Rao Y, Shi Z, Liu L, Chen C, Zhao Y. Hypertension impact on health-related quality of life: a crosssectional survey among middle-aged adults in Chongqing, China. International journal of hypertension. 2016.
4. Stewart, Anita L., Ron D. Hays, and John E. Ware. "The MOS short-form general health survey: reliability and validity in a patient population." Medical care 1998;26.7:724-735.

5. Denise F, Cheryn P. The content validity index: Are you sure you know what's being reported? Critique and recommendations. Research in Nursing and Health 2006; 29:489-497.

6. Naveen B, Mahaboojan M, Padmanabha YR, Narayana G. Impact of clinical pharmacist mediated patient counselling on health-related quality of life in hypertensive patients. Indian Journal of Pharmacy Practice. 2014; 7(1):21-29.

7. Gurcay E, Bal A, Cakci A. Health-related quality of life in first-ever stroke patients. Annals of Saudi medicine. 2009 Jan; 29(1):36-40.

Source of Support: The author(s) received no financial support for the research, authorship, and/or publication of this article.

Conflict of Interest: The author(s) declared no potential conflicts of interest with respect to the research, authorship, and/or publication of this article.

For any question relates to this article, please reach us at: editor@globalresearchonline.net New manuscripts for publication can be submitted at: submit@globalresearchonline.net and submit_ijpsrr@rediffmail.com 